\title{
A COMPARISON OF HEDONIC AND UTILITARIAN DIGITAL PRODUCTS BASED ON CONSUMER EVALUATION AND TECHNOLOGY FRUSTRATION
}

Bidyut Bikash Hazarika https://orcid.org/0000-0001-8279-6425

Mohammadreza Mousavizadeh https://orcid.org/0000-0002-8564-6366

Mike Tarn https://orcid.org/0000-0002-4229-3900

Western Michigan University, Kalamazoo, MI, USA

\begin{abstract}
This study explores how hedonic mobile applications (apps) compare to utilitarian apps in consumer evaluation. We posit that achieving a set of passionate consumers is a pre-cursor to product success in markets, whereas technology frustration is a negative hindrance to the product success. Also, we argue that technology frustration may act as a negative complementing factor to consumer passion, and this effect is higher for hedonic products than utilitarian products. We contextualize our study to the android apps, and used a dataset that tracked 19,121 apps in the android market for three months and coded our variables from this dataset. We conducted empirical analysis and found support for our hypotheses. This study contributes to the information systems and marketing literature in providing a new dimension associated with consumer evaluation of digital products, and draws evaluative comparisons between hedonic and utilitarian digital products.
\end{abstract}

Keywords: consumer passion, technology frustration, digital products, apps, hedonic and utilitarian products, consumer evaluation

Manuscript first received: 2019/01/08. Manuscript accepted: 2019/10/04

Address for correspondence:

Bidyut Bikash Hazarika, Western Michigan University, Kalamazoo, MI, USA. Email: bidyut.hazarika@wmich.edu

Mohammadreza Mousavizadeh, Western Michigan University, Kalamazoo, MI, USA. Email: m.mousavizadeh@wmich.edu

Mike Tarn, Western Michigan University, Kalamazoo, MI, USA. Email: mike.tarn@wmich.edu 


\section{INTRODUCTION}

Continuous development in mobile technologies and related applications (apps) has emerged to converge in the apps market space. Starting with a handful of apps in 2008, the Apple Store had more than a million apps for sale in 2015. Similar trends are observed in the Android and Microsoft apps stores as well. Many companies are using mobile apps as traditional trade channels. Revenue from app users is projected to increase from \$10.3 billion in 2013 to \$25.2 billion in 2017 (IDC, 2013).

Several challenges persist in the mobile apps market. First, app markets are emerging to be highly competitive. So much so that even free apps do not guarantee a large number of user downloads or usage. Second, sustained use of a specific app is a critical challenge. Studies find that consumers often drop using an app after 30 days (Böhmer, Hecht, Schöning, Krüger, \& Bauer, 2011). In contrast, apps relevant to specific industries such as games, or entertainment avenues have more sustained and constant usage (Shin, Hong, \& Dey, 2012). In other words, there are two strong customer orientations in app markets, (a) highly attractive entertainment and games apps, and (b) a seemingly not-so-attractive segment of trade or storefront apps. Consumer attraction and subsequent use of apps are essential for app developers and apps-using enterprises for the reasons of revenue earning potential, reputational aspects and scale effects associated with popularity.

The challenge of consumer attraction to apps is reflected in two dimensions. First, prolonged use of apps leads to a set of addicted consumers - which is discernible in apps relevant to games or social media applications. On the contrary, other apps remain unnoticed for a lengthy period; for example, consumers may not pay attention to an insurance-claim filing app except and unless using it at the time of accidents. The second dimension of the attractiveness of apps may be reflected in their negative response to the app's technical and usability features, reflected in the dissatisfaction or grunt associated with apps use. Thus, exploring how consumer passion and frustration is related to the consumer evaluation of the apps is an essential precursor to the success of apps. Further, how this relationship is contingent on the apps' characteristics specific to the value perception by the consumer, remains a wide gap in existing literature.

In this study, we explore two research questions: (1) what is the influence of consumer passion and frustration on consumer evaluation of apps, (2) how the relationships of consumer passion and frustration on consumer evaluation are differentiated by hedonic and utilitarian apps. Based on prior studies (der Heijden, 2004; Mikalef, Giannakos, \& Pateli, 2013; Wakefield \& Whitten, 2006), we denote the term hedonic to those apps that "aim to provide self-fulfilling value to the user"; whereas utilitarian apps "aim to provide instrumental value to the user." We posit that achieving a set of addicted consumers is a pre-cursor to product success in markets, whereas technology frustration due to technology failures is a negative hindrance to the product success. Also, we argue that consumer passion can act as a substitutive aspect to overcome technology frustration for the product in the market, and this substitution effect is higher for hedonic products, such as game and social media apps than other apps. Although a few prior studies note the importance of hedonism as an instrumental concept in information systems design, development and usage (Chung \& Tan, 2004; Sun \& Zhang, 2006; Venkatesh, Thong, \& Xu, 2012), this is still an unexplored area in the context of the app. This study tries to fulfill this gap in the existing research.

To conduct the empirical analysis for this study, we used a secondary dataset that tracked 39015 apps in the Android market for one month and coded our variables from this dataset. We conducted empirical analysis and found support for our hypotheses. This study contributes to the information 
systems and marketing literature in providing a new dimension of consumer passion and frustration associated with consumer evaluation of digital products and draws evaluative comparisons between hedonic and utilitarian digital products. We discuss managerial implications and contributions of the study.

\section{LITERATURE REVIEW}

Existing information systems has differentiated the hedonic and utilitarian use of information technology, through the lens of user behavior as a result from a reasoned appraisal of pre-adoption beliefs of the IT artifact (Mallat, 2007; Venkatesh, Morris, Davis, \& Davis, 2003). A few studies have extended the hedonic and/or utilitarian lens to mobile computing (Dickinger, Arami, \& Meyer, 2006; Wakefield \& Whitten, 2006) and other general IT products (der Heijden, 2004; Lin \& Bhattacherjee, 2010).

Consumer passion measures the zeal with which an app enthralls a consumer. The app fulfills a consumer need, whether functional or social, resulting in positive affect, or emotive attachment, to the app. Other researchers also identify consumer passion as consistent with the description as mentioned earlier. For instance, Belk, Ger, \& Askegaard (2003) define consumer passion as "a passion born between consumption fantasies and social situational contexts". When someone becomes dependent on a particular type of technology and have to use it repeatedly, the user becomes passionate about the product (Holden, 2001). The existence of such passion for digital artifacts has been proven by Turel et al. (Turel, Serenko, \& Bontis, 2010).

Technology frustration is the result of the failure a consumer faces when technology fails to achieve its desired task. In an individual level, technology frustration can be defined as the negative emotion due to ineffective use of a technology (Bessiere, Newhagen, Robinson, \& Shneiderman, 2006). In case of an app, the primary cause of technology frustration is an inaccurate description, not enough engagement, not user-friendly, crash and other usage problems. Technology frustration leads to dissatisfaction, and loss of self-efficacy and eventually lead to consumer uninstalling the app and leaving a bad review (Fogel \& Zachariah, 2017). Technology frustration may also lead to disruption in the workplace, slow functionalities and not using the app (Lazar, Jones, Hackley, \& Shneiderman, 2005) or also may lead to high levels of anxiety and anger on part of the user (Wilfong, 2006) eventually leading the user to stay away from the technology (Lenhart, Purcell, Smith, \& Zickuhr, 2010). As pointed out by Guchait and Namasivayan (Guchait \& Namasivayam, 2012), all the factors mentioned above create a bad response for the technology in the market.

Prior research has shown that to be successful, consumer-oriented digital products need a good value proposition, a well-conceived revenue model and availability of critical resources. In the case of apps, the key resources that come into consideration are the design, the working and the integration of the app in the app store. In a digital world, four components: scope, scale, speed and sources of value creation and capture work together to create value for the product (Bharadwaj, El Sawy, Pavlou, \& Venkatraman, 2013). In other words, in an app store, consumer evaluation drives its value creation. The factors that reflect the evaluation of an app are its pace of spread, its continued usage and the scale and scope of its usage (Brown, Venkatesh, \& Goyal, 2014a, 2014b). Even though product evaluation has been studied extensively in marketing literature, the role of technology in the evaluation process has remained unexplored and is a point of contention for both academicians and practitioners alike. 


\section{THEORETICAL FRAMEWORK}

We base the theoretical foundation for this study on flow theory and cognitive absorption concepts, to posit that the evaluation of an app is dependent on the involvement-flow and holding power due to absorption associated with the use of the app. Flow is the standard mode of experience and holistic sensation related to the act of total involvement or absorption with any activity (Csikszentmihalyi \& Csikszentmihalyi, 1992). When applied with information usage, prior studies suggest that flow helps in enriching an online consumer experience (Knijnenburg, Willemsen, Gantner, Soncu, \& Newell, 2012), providing strong awareness in product quality in electronic service context (Xu, Benbasat, \& Cenfetelli, 2013), the relationship between website quality and product quality perceptions (Wells, Valacich, \& Hess, 2011) and enhancing brand equity (Nah, Eschenbrenner, \& DeWester, 2011). Other studies in information systems research have used the flow theory in understanding user or consumer experiences associated with an artifact or product (Ghani, Supnick, \& Rooney, 1991; Hoffman \& Novak, 1996; Trevino \& Webster, 1992).

Extending the flow concept of digital products, we posit three sets of arguments in this study. First, passion is a state of higher flow and cognitive absorption that leads to higher consumer evaluation. Second, technology frustration leads to a temporal dissociation in the flow and absorptive states, leading to a drop in the evaluation. In the presence of both passion and frustration, the dimensions associated with the passion play a heightened enjoyment role to improve evaluation. The third line of argument extends the later one to posit that for hedonic products, the dissociation associated with frustration state may lead to permanent dispassion for hedonic apps than utilitarian apps to reduce the consumer evaluation.

The concept of cognitive absorption in the context of IT usage behavior has been widely studied in the IT literature. Agarwal and Karahanna (Agarwal \& Karahanna, 2000) found that playfulness and personal innovativeness are two individual traits that play a significant role in human computer interactions. The "holding power" or attractiveness of a technology depends on two factors: access and the ability to adopt the online persona. Extending this argument to mobile apps, we can argue that in case of hedonic apps, users would be more passion because of its playfulness and users ability to adopt the personality of the gamer, leading to a higher consumer evaluation compared to utilitarian apps.

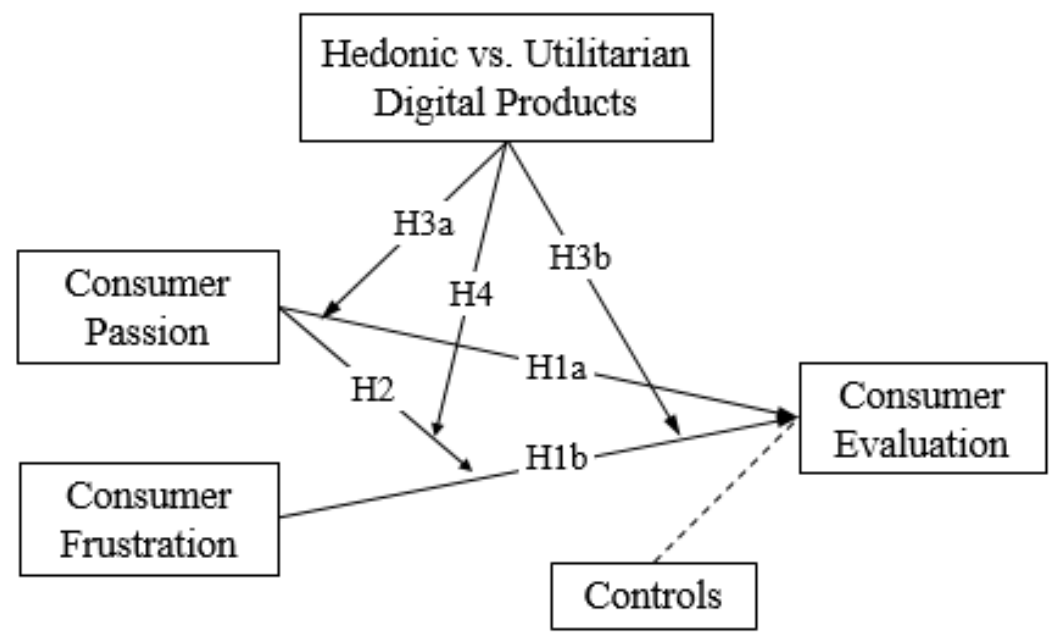

Figure 1 - Conceptual Model 
Based on the above theoretical positioning, we propose a conceptual model (see figure 1) that presents three sets of relationships: 1) consumer passion has a direct impact on consumer evaluation 2) technology frustration has a direct impact on consumer evaluation and 3) hedonic products (e.g. games, social media apps etc.) moderates the relationship between consumer passion and consumer evaluation as well as technology frustration and consumer evaluation. The next section we draw up the hypotheses we would test in this paper.

\section{Hypotheses}

Passion is a trait when a consumer has strong feelings with a particular product and keeps using it repeatedly over and over again. In the case of apps, if a consumer keeps checking an app repeatedly to check its content, we can classify them as passionate users. This repeated use of the app leads to eventual being an eager consumer. Consumer passion indicates not only the liking of consumers for an app due to its appeal, function or on the attribute to meet a specific unique need; but also that the app has the potential to be sustained in the market due to a set of passionate consumers. For example, a fitness app would have a good appeal for the consumer segment that wants to stay fit, and hence, would have generated a set of consumers who use and get passionate about it. These passionate consumers would then derive higher benefits, be testers, will work towards the improvement of the app by providing feedback and in general help in mitigating the aspects related to the frustration technology issues. The features such as an app having a great design, integration, functionality contribute towards creating passion among the users. An app in a workplace works smoothly as advertised can lead to greater productivity and utilization from its workers resulting in good evaluations, leading to positive word of mouth and better customer evaluation. Based on these arguments, we posit that:

H1a: Consumer passion has a positive effect on consumer evaluation of apps.

Technology frustration deals with the negative emotions that individuals feel with the use of technology. In the context of apps, if an app doesn't perform as it is supposed to, it leads to consumers discontinuing the app, or being dissatisfied by the app. The performance of the app in this study is based on factors such as crash, design, usage, integration and functionality issues. Prior studies note that technology frustration leads to loss of the users' self-efficacy and subsequent personal dissatisfaction. For example, when the user used an app for a game or to stream a movie, and the app fails or crashes; then it leads to discontinuation of the game or the movie, leading to the dissatisfaction of the user.

Similarly, an apartment finder app, or a business networking app, if do not work properly as desired, lead to failure of the business and loss of productivity and revenue. Often the resulting negative word-of-mouth from dissatisfied users will lead to less adoption of the app which in turn will lead to decrease the consumer evaluation of the app, finally leading to the death of the app. Prior studies (Guchait \& Namasivayam, 2012) note that the grunt felt by consumers when shared in a public forum creates a negative image of the product in the market. Hence we hypothesize that:

H1b: Technology frustration has a negative effect on consumer evaluation of apps.

We contend that consumer passion is a moderating factor in the relationship between technology frustration and consumer evaluation, for at least two reasons. Passionate consumers of an app love the app. They may be willing to forgive some issues that are at the surface level, such as somewhat a bad interface. But when the app crashes or gives a bad functionality problem, due to technical issues, passionate consumers may leave the app forever. They may switch to another app, or may 
get passionate about another app. So even though apps that have been sustained in a market for substantial period reflect on their good usage and functionality; and due to a set of consumers that are passionate about the apps, but when technological issues and resulting frustration is high, apps face the frustration of the consumers at a higher level. Thus, we argue that even though repeated use of the app will contribute to an increase of numbers of passionate user; but consumers are unforgiving to crashes, and high levels of technological functionality issues. Based on the argument, we hypothesize:

H2: Technology frustration has a negative complementing effect on consumer passion for influencing the consumer evaluation of apps.

When people decide to use an app, it can be due to two values: utilitarian and hedonic behavior. Utilitarian behavior is more relational and task-related. We classify utilitarian apps as those apps that are effectively used by consumers. For example, apps that are downloaded to track finances, medical records are all classified as utilitarian apps: apps that are used to achieve specific tasks. Hedonic apps, on the other hand, are apps that are used for fun and playfulness vs. task completion (Hirschman \& Holbrook, 1982). Thus, we can say that consumers mostly use hedonic apps for entertainment value such as arousal, heightened involvement, perceived freedom, fantasy fulfillment, and escapism.

Hedonic apps will have more success as they are more likely to be used more often compared to utilitarian apps. The degree of passion will also be high for these apps as well. If hedonic apps work seamlessly, the consumer evaluation will be much higher as people would have a greater evaluation for these apps. In the case of utilitarian apps, people use them only to achieve specific task and not for its enjoyment value. So, if a utilitarian app crashes or has technical glitches, the consumer will be more forgiving compared to a hedonic app. Based on these arguments, we can hypothesize that:

H3a: The positive effect of consumer passion on consumer evaluation is higher for hedonic apps than utilitarian apps.

H3b: The negative effect of technology frustration on consumer evaluation is higher for hedonic apps than utilitarian apps.

We have previously hypothesized that consumer passion has a negative effect on technology frustration on consumer evaluation. This effect is amplified when we take into consideration the type of app: hedonic vs. utilitarian. For example, if the app is a gaming app and the consumers are passionate about the app, and the app crashes or have technical issues, consumers are more willing to forgive the app developer since they are hooked with the app. The case is opposite when we take into consideration utilitarian apps that consumers use to fulfill their daily tasks, e.g. an app for banking if keeps on crashing or facing technical difficulties, will create a much higher technology frustration ultimately resulting in a weak consumer evaluation.

H4: The attenuating effect of consumer passion on technology frustration is lower for hedonic apps than utilitarian apps.

\section{METHODOLOGY}

This study uses secondary data collected by a consulting company. The company tracks mobile apps in android markets and provides analytical insights based on monitoring information. The data for this study spans for three months of September 2016-January 2017. We used the data from the first week as the reference week, and the second week as the reference for changes in ratings, reviews and the other variables used. 
The data was collected for the top 40,000 apps in the Android market for the month of OctoberNovember 2016. We could not consider 5876 dead apps for our analysis. They were new apps that were added to the market after the first focal week. After careful consideration, we found 10,000 of those apps were in a language other than English, had illegible names, or were duplicates of the already existing apps. Also, we excluded 5003 apps as there was no change in ratings or number of people who rated or reviewed the apps in the focal week and the subsequent weeks. We were left with 19,121 apps for our analysis. We then created a panel data for two and a half month.

Figure 2 provides the way we collected the data. Table 1 describes variables we used in this study. Table 2 describes statistics and Table 3 presents pair-wise correlation amongst the variables. The dependent variable in our model is the Consumer Evaluation in a month. This variable is calculated as the difference in the product of average rating and raters in that month, per original rater at the beginning of the month (see the calculation described in Table 1). Using both average ratings per week and the total number of raters provides both a measure of score, and a measure of popularity in a single variable that assesses overall rating impact. By measuring the overall impact score across the period, an index is developed based on the benchmark measure of the first week. This index is our dependent variable, Consumer Evaluation. Aggregate measures of this kind have been used before, one famous one that uses a combination of two variables is Gross Rating Points, still extensively used as a measure of the overall size of an advertising campaign. Similarly, by combining two crucial app rating measures, namely the average rating score and the total number of raters, Consumer Evaluation measures the app's overall impact rating, both regarding quality and quantity.

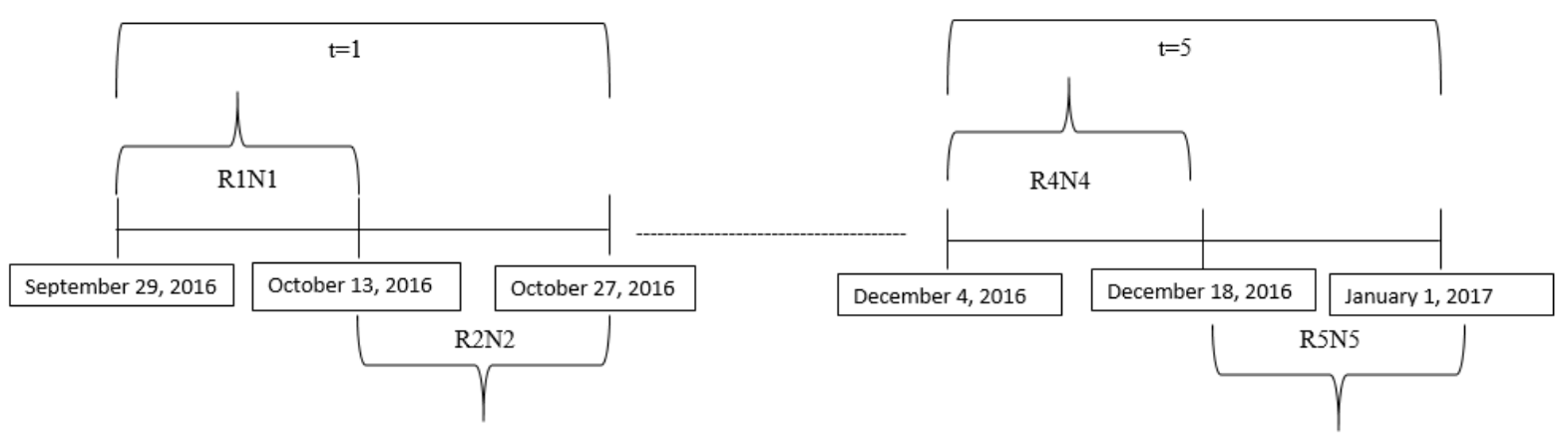

Figure 2 - Time Structure of Research Design and Data Collection

The focal independent variable in this study is Technology Frustration which indicates the frustration due to technical glitches, issues or failures in using the app. This variable is coded by mining the text reviews of each app in the months' time. The index measures the percentage of reviewers that discuss technical issues, frustrating problems, challenges in usage, and crashing of the app. Thus it provides an aggregate measure of technology frustration with the app in the market. 
Table 1 - Description of Variables

Variable

Consumer Evaluation

Consumer Passion

Technology Frustration

Download Volume
Description and Operationalization

An index calculated as follows:

Consumer Evaluation $=\mathrm{R} 2 * \mathrm{~N} 2-\mathrm{R} 1 * \mathrm{~N} 1$

Where,

$\mathrm{R} 2=$ Average rating of the APP in week 4

$\mathrm{N} 2=$ Total number of raters of the APP in week 4

$\mathrm{R} 1=$ Average rating of the APP in week 1

$\mathrm{N} 1=$ Total number of raters of the APP in week 1

Definition: A powerful and persistent urge by the consumers to use or buy or interact with the app. This variable is coded by mining the text reviews of each app in the panels' time. The index measures the percentage of reviewers that discuss admiration, devotion for and exaltation for the app within the focal weeks.

Definition: Annoyance felt by the consumers for the APP in the market due to crash, technology or any other integration issues.

This variable is coded by mining the text reviews of each App. We calculated the percentage of reviewers that discuss technical issues, frustrating problems, challenges in and crashing of the app.

To what extent consumers have sustained the app in the market. The variables is operationalized by measuring the total download volume of the app until the focal week. This was a range variable with unequal ranges. We coded download volume as a continuous variable by taking the mid-point of the range provided. (E.g. if the download range is $10,000-50,000$, we used the midpoint 30,000 as the number of downloads). We then divided the number of downloads $1,000,000$.

Age of the app, indicating how long the app has existed in the android market.

Age The variable was coded as the difference between the focal week and the release date of the app.

When was the app last updated. The variable was coded Update as the difference between the focal week and last date when the APP was updated.

Apps that are used by users for pleasure or achieving a

Hedonic thrill (e.g. games, music, sports etc.)

The variable is coded as $1=$ hedonic app, $0=$ not a hedonic app.

The category of the app, as pre-defined in the android market. We coded dummy variables for each category Category to include in the analysis. We have the following 9 categories: C_Productivity, C_Finance, C_Medical, C_Health\&Fitness, C_Communication, C_Simulation, C_Photography, C_Weather, C_Travel\&Local 
The second independent variable is Consumer Passion, for the app in the market that reflects the appeal of the app to the consumers as a powerful and persistent product, and is measured by mining the text reviews of each app in the panels' time. The index measures the percentage of reviewers that discuss admiration, devotion for and exaltation for the app within the focal weeks.

The third independent variable is whether the app is hedonic or utilitarian app (1=hedonic, $0=$ utilitarian). The download volume varies from 100 to 2,500,000, with an average download of 88,000 for the apps in our sample. The third dependent variable is the age of the app in the market. The age of the apps varies from .02 to 5.76 years. The fourth dependent variable is the age of the app since its release date. The average app in our sample is 1.5 years old, with the maximum age being 5.72 years and the minimum is two months. The final dependent variable of the app is the time of the last update. The average app was last updated seven months ago with the maximum update was five years ago. We also coded nine dummies indicating the category of the app. Figure 3 provides the coding of key variables.

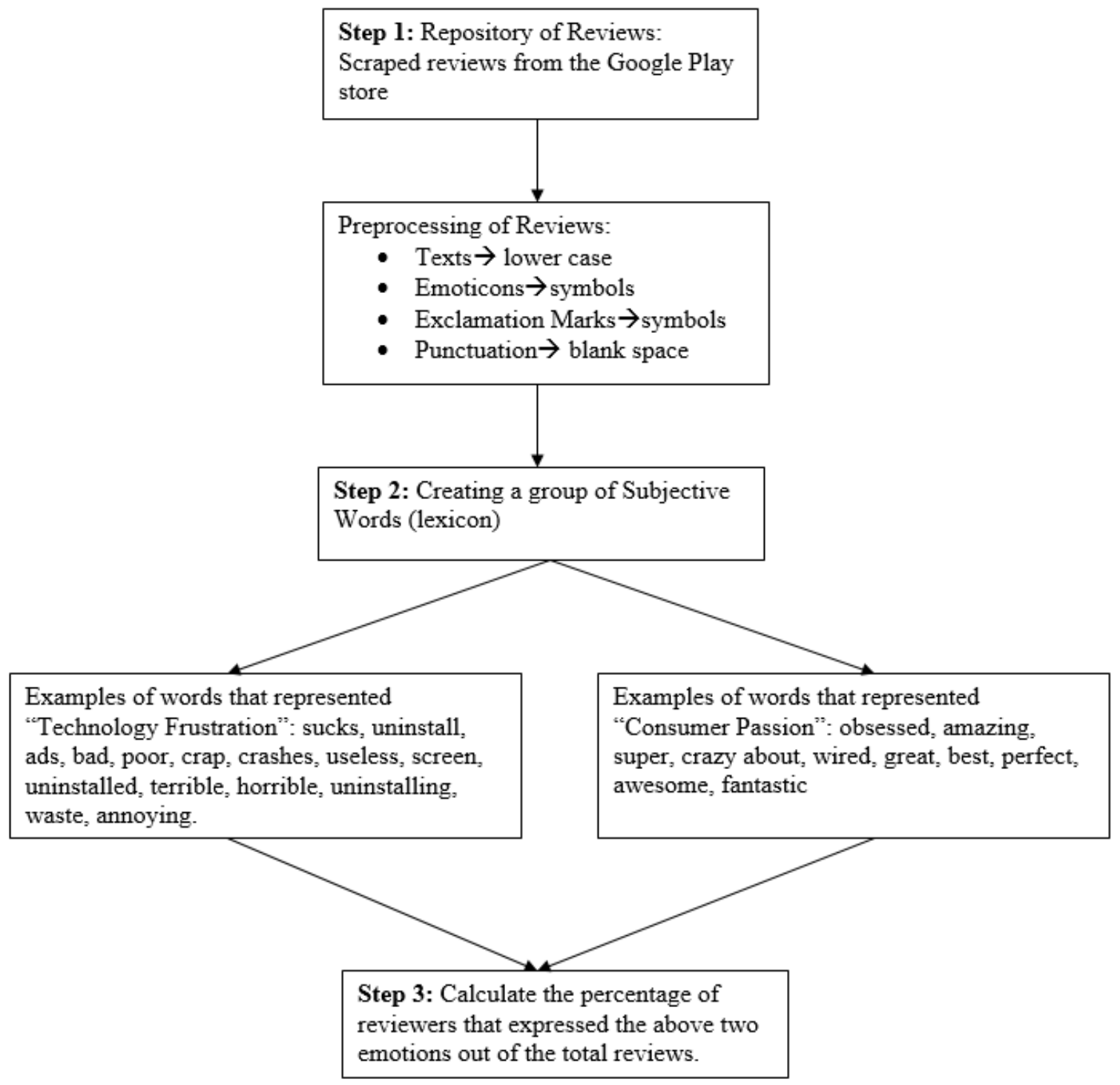

Figure 3 - Coding of Key Variables using Text Mining 
Table 2 - Descriptive Statistics

\begin{tabular}{lcccccccc}
\hline Variable & Obs & Mean & $\begin{array}{c}\text { Std. } \\
\text { Dev. }\end{array}$ & Min & Max & $\begin{array}{c}\text { Hedonic Apps } \\
\text { Mean } \pm \text { SD (N) }\end{array}$ & $\begin{array}{c}\text { Utilitarian Apps } \\
\text { Mean } \pm \text { SD (N) }\end{array}$ & $\begin{array}{c}\text { Difference in } \\
\text { mean (T-test) }\end{array}$ \\
\hline Consumer Evaluation & 19121 & 2.01 & 16.40 & 0.19 & 90.42 & $1.64 \pm 1.28(9975)$ & $2.08 \pm 1.11(8161)$ & $0.43^{* * *}$ \\
Consumer Passion & 19121 & 5.74 & 1.09 & 0.12 & 9.557 & $5.59 \pm 1.63(9975)$ & $5.47 \pm 0.26(8161)$ & $0.64^{* * *}$ \\
Technology Frustration & 19121 & 6.12 & 6.39 & 0 & 64 & $6.23 \pm 0.89(9975)$ & $6.32 \pm 0.12(8161)$ & $0.34^{* *}$ \\
Hedonic & 19121 & 0.55 & 0.50 & 0 & 1 & & & \\
Age & 19121 & 1.57 & 1.09 & 0.02 & 5.72 & $1.36 \pm 0.11(9975)$ & $1.59 \pm 0.12(8161)$ & -0.08 \\
Update & 19121 & 0.65 & 0.83 & 0.02 & 5.72 & $0.65 \pm 0.83(9975)$ & $0.59 \pm 0.76(8161)$ & -0.76 \\
Download Volume & 19121 & 0.88 & 4.97 & 0.01 & 250 & $0.83 \pm 1.39(9972)$ & $0.75 \pm 1.54(8161)$ & 0.89 \\
\hline
\end{tabular}

$* * * \mathrm{p}<0.01, * * \mathrm{p}<0.05,{ }^{*} \mathrm{p}<0.1$.

Table 3 - Pair-wise Correlations amongst Variables

\begin{tabular}{lcccccccc}
\hline & Variable & 1 & 2 & 3 & 4 & 5 & 6 & 7 \\
\hline 1 & Consumer Evaluation & 1.00 & & & & & & \\
2 & Consumer Passion & 0.09 & 1.00 & & & & & \\
3 & Technology & -0.03 & -0.26 & 1.00 & & & & \\
4 & Frustration & & & & & & \\
5 & Hedonic & 0.02 & 0.12 & -0.24 & 1.00 & & & \\
6 & Age & -0.01 & 0.00 & 0.00 & 0.00 & 1.00 & & \\
7 & Update & 0.00 & -0.01 & 0.00 & 0.01 & 0.05 & 1.00 & \\
\hline
\end{tabular}

All correlations greater than 0.10 are statistically significant at $\mathrm{p}<0.01$

Correlations with the category dummies all are less than 0.1 .

\section{Estimation Model}

We used panel data for our analysis. To decide between fixed or random effects, we run a Hausman test where the null hypothesis is that the preferred model is the random effect vs. the alternative of fixed effect (Green, 2008). The Hausman test tests whether the unique errors are correlated with regressors, the null hypothesis is they are not. The Hausman test wasn't insignificant and hence we used a fixed effect model. We used the below estimation to model the consumer rating shift model because the ConsumerEvaluation is a continuous variable.

$$
\text { ConsumerEvaluation }_{i}=\beta X_{i t}+\alpha+u_{i t}+\varepsilon_{i t}
$$

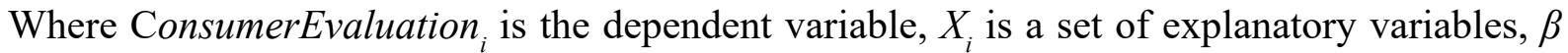
is a vector of parameters, $u$ is the between-entity error and $\varepsilon$ are disturbances associated with each observation. 


\section{RESULTS}

We first tested the direct relationship between consumer passion on consumer evaluation (refer to Column 1 of Table 4). We then included one interaction term each to test their individual interaction effects on consumer evaluation shift (Column 2-4, Table 4), and finally, tested for joint effects of all interaction terms in a model (Column 5 of Table 4).

We find support for H1a as, the coefficient for consumer passion is positive and significant in the direct effect model (Column 1 of Table $4, \beta=0.144, \mathrm{p}<0.01$ ). We also find support for H1b which predicted that technology frustration would have a negative on effect on consumer evaluation (Column 1 of Table 4, $\beta=-3.12, p<0.01$ ). The interaction term of Technology Frustration X Consumer Passion is negative and significant in the interaction model (refer to column 2 of Table $4, \beta=-5.83$, $\mathrm{p}<0.01)$. The interaction hypothesis predicts that for the apps that have higher technology frustration, consumer passion will have a lower effect.

We find support for $\mathrm{H} 2 \mathrm{a}$ which predicted that consumer passion on consumer evaluation is higher for hedonic apps than utilitarian apps. The interaction term of Consumer Passion X Hedonic is positive and significant in the interaction effects model (refer to column 3 of Table $4, \beta=3.49$, $\mathrm{p}<0.01)$. The interaction hypotheses $\mathrm{H} 2 \mathrm{~b}$ predicted that negative effect of technology frustration on consumer evaluation is higher for hedonic apps than utilitarian apps. We find support for this hypothesis as the interaction term Technology Frustration X Hedonic is significant and negative in the interaction effects model (Column 4 of Table $4, \beta=-0.24, \mathrm{p}<0.05$ ).

Finally, $\mathrm{H} 3$ is also supported, as the coefficient of the three-way interact term Consumer Passion $X$ Technology Frustration X Hedonic is significant and negative (see Column 5, Table 4, $\beta=-0.411$ $\mathrm{p}<0.01$ ). This hypothesis predicted that consumer passion for technology frustration on consumer evaluation is increased in case of hedonic apps and the opposite is true for utilitarian app.

\section{Robustness Tests and Interaction Plots}

We checked the robustness of our findings with different tests. First, F-tests of joint significance of the interaction terms were rejected, suggesting that the interaction terms do not have any combined null effect. Second, we performed Harman's one-factor test and the marker variable test (Lindell \& Whitney, 2001) to test the common method variance for our variables as they are taken from somewhat similar sources. In Harman's test, no single major factor emerged, and in the markervariable tests, the correlations among the variables did not change significantly after accounting for common method variance. Thus, results of both tests suggest that common method bias is not a significant concern.

Variance inflation factors (VIFs) for all the estimation models were calculated to test for multicollinearity. The calculated VIF for the direct-effect model was 1.9, which was within the acceptable range and multi-collinearity is not an issue in this case. To address the issue of multicollinearity in case of the interaction terms, we mean-centered all the continuous variables by subtracting the variable mean from each value (Aiken, West, \& Reno, 1991). All the individual variables in the interaction terms had a VIF of less than 7 and all the models had a mean VIFs less than 5. Hence, we can suffice that multicollinearity is not an issue in our estimation.

Fourth, White's (White, 1980) tests for heteroskedasticity did not suggest the presence of heteroskedasticity. Nevertheless, as suggested in the literature (Greene, 2008), we estimated our 


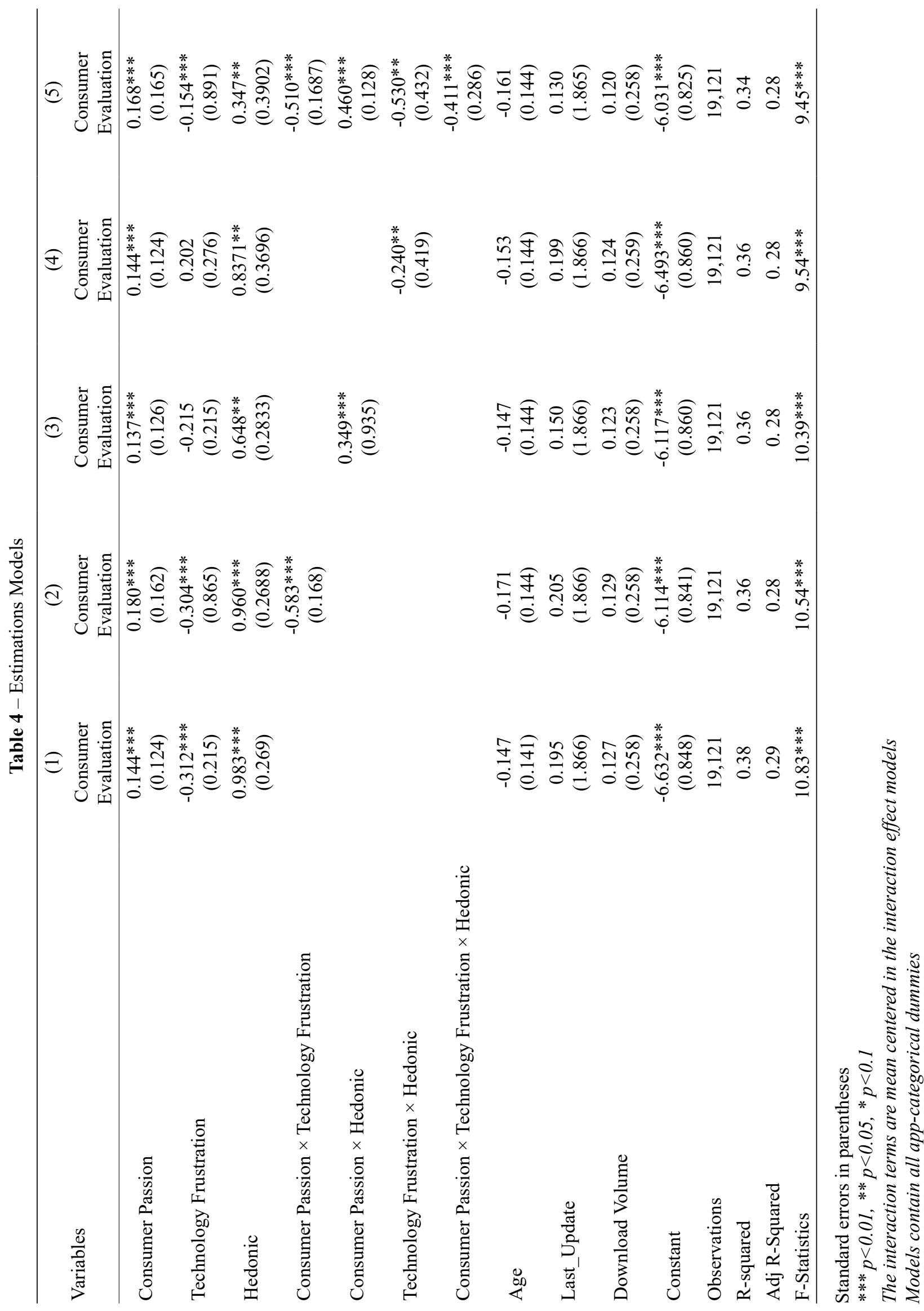


models with robust standard errors in all our estimations and compared to results without robust standard errors to find no significant changes across the two estimated results. Last, we performed several diagnostic checks including testing for normality of residuals, outliers, and influential observations, and found no problems or violations of assumptions (Greene, 2008).

To aid in the interpretation, we plotted the interaction effects (see Figures 4A to 4D). The first interaction effect 4A shows that with high technology frustration, the slope of the impact of consumer passion on consumer evaluation decreases. Figure 4B shows that for hedonic apps the slope of the impact of consumer passion on consumer evaluation is higher than that of utilitarian apps. Similarly, figure 4C shows that technology frustration in case of hedonic apps is much higher when compared to the utilitarian apps. The 3 way interaction effect between the variables are shown in figure 4D. Technology frustration and consumer evaluation is high for hedonic compared to utilitarian apps.

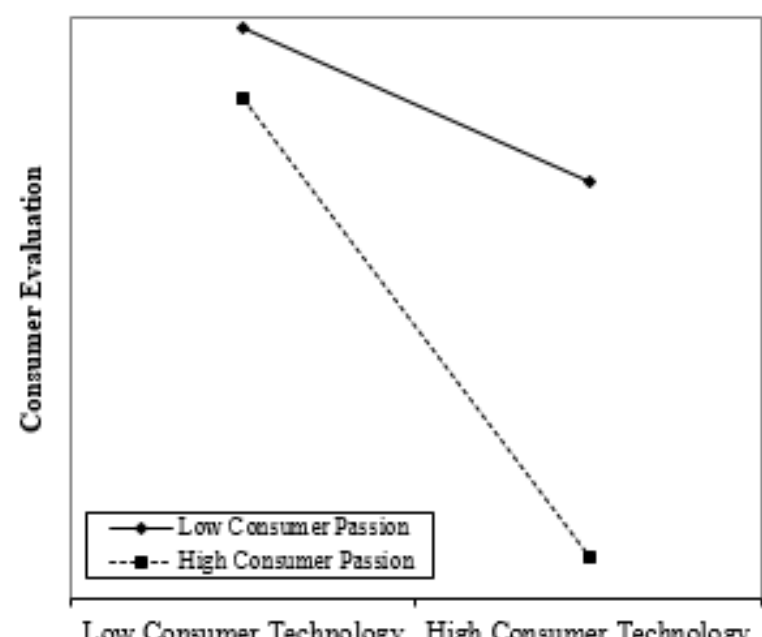

Frustration

A

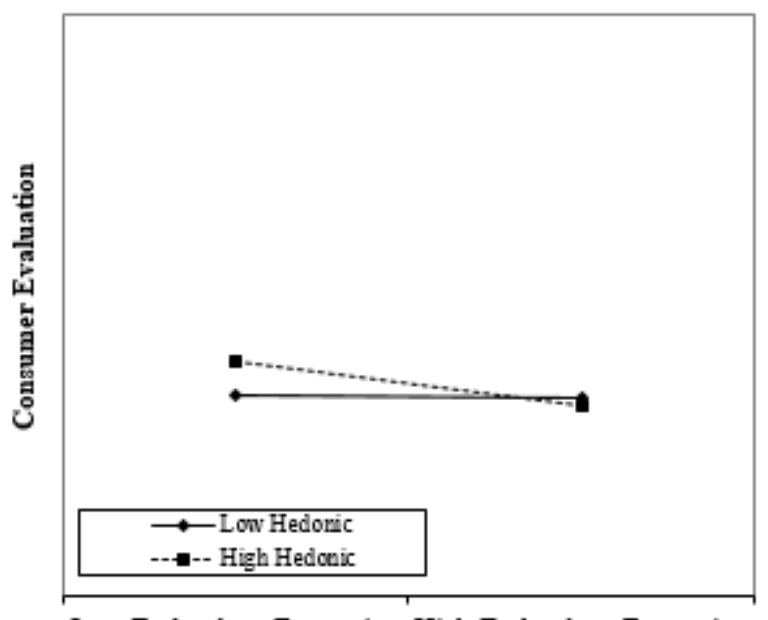

Low Technology Frustration High Technology Frustration

C

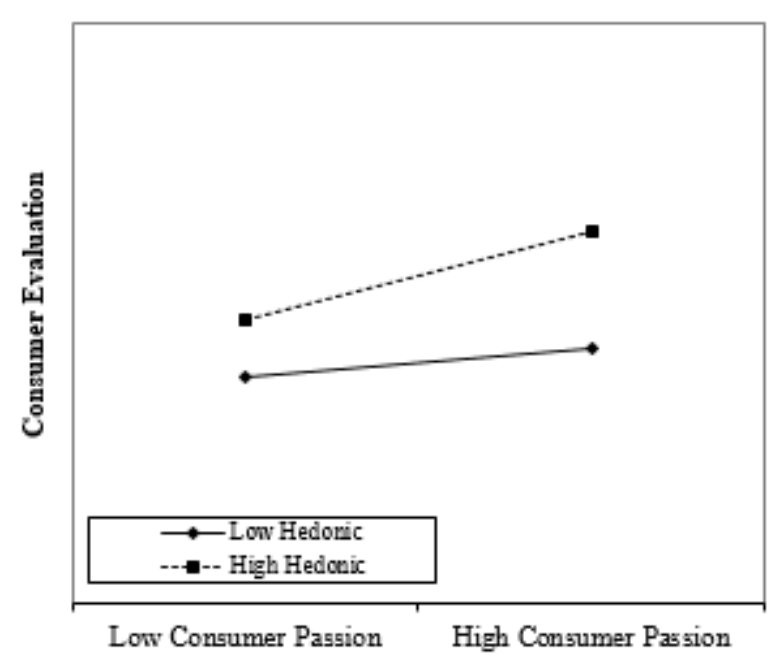

B

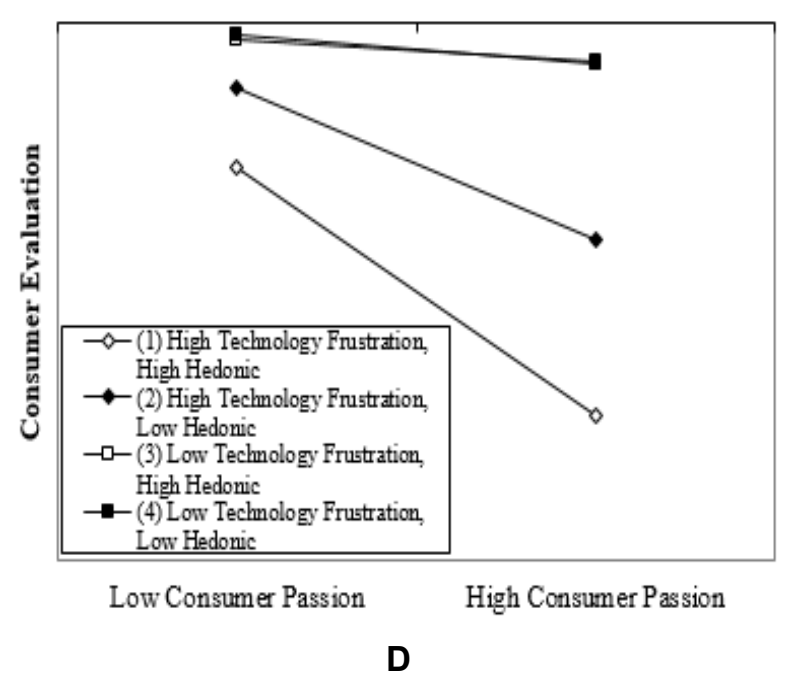

Figure 4 - Interaction Effect Plots 


\section{DISCUSSION}

This study reports five findings. First, technology passion has a significant positive effect on consumer evaluation. Second, technology frustration has a negative association with consumer evaluation. Third, even with a positive influence of consumer passion, with high technology frustration, the consumer evaluation goes down. Fourth, hedonic apps score better for the effect of consumer passion on evaluation, while they score worse for the effect of technology frustration on evaluation. Finally, the negative interaction effect of consumer passion and technology frustration is higher for hedonic apps than utilitarian apps.

The first managerial implication of this study is that "hedonistic" aspect of apps has an attractive effect for consumers. To the extent that hedonic apps influence higher consumer app usage than utilitarian apps, this has high relevance to influence app design. Plausibly, app designs can be oriented to have more "hedonist" design aspects, even though they have utilitarian value. For example, a banking app may design the front-end of the app in a way such that consumers may find it a bit entertaining to use the features (Srivastava, Chandra, \& Theng, 2010).

A second managerial implication of this study is that irrespective of a great proposition that an app is useful for customers, technical design and integration play a highly valuable role in consumer acceptance of the app. Hence, developers should pay more attention to the technical aspect of the apps. Moreover, app developers should be careful in the design and development aspects of an appwhich is often a forgotten aspect due to the low-cost development regime of apps developments. Also, identifying passionate consumers and pricing of the apps play important role for the success of an app.

Finally, as much as an app's release is important, taking feedback from consumers and tracking evaluation regularly (almost on a daily basis) is critical for an app's success. While such feedbacks and market mechanisms such as release controls and existing strategies are seen in consumer-oriented products such as movies or music products, apps markets need to implement such a system.

Regarding research contributions, this study is the first one to explore the comparative effects of consumer behavioral factors associated with apps adoption; with a set of nuanced variables such as passion, frustration associated with hedonic and utilitarian apps (Venkatesh, Brown, Maruping, $\&$ Bala, 2008). These contributions inform the existing information systems literature and research associated with apps usage. Further, indirectly this study identifies the critical role of design and evaluation factors related to IT business value, specifically in the apps market context. Moreover, it also informs to the vast literature in the marketing on the product feature or aspects that influence consumer evaluation of products. Future research may explore nuances associated with technology frustration with a deeper lens.

In conclusion, the objective of this study was to explore to what extent consumer passion and technology frustration influences consumer evaluation of apps; and how these effects differ across utilitarian and hedonic apps. We analyzed secondary data for more than 18,000 android apps and found support for all our hypotheses. This study contributes to the research on the digital business strategy for apps markets. 


\section{REFERENCES}

Agarwal, R., \& Karahanna, E. (2000). Time flies when you're having fun: cognitive absorption and beliefs about information technology usage 1. MIS Quarterly, 24, 665-694.

Aiken, L. S., West, S. G., \& Reno, R. R. (1991). Multiple regression: Testing and interpreting interactions.

Belk, R. W., Ger, G., and Askegaard, S. 2003. "The Fire of Desire: A Multisited Inquiry into Consumer Passion," Journal of consumer research (30:3), pp. 326-351.

Bessiere, K., Newhagen, J. E., Robinson, J. P., \& Shneiderman, B. (2006). A model for computer frustration: The role of instrumental and dispositional factors on incident, session, and post-session frustration and mood. Computers in human behavior, 22, 941-961.

Bharadwaj, A., El Sawy, O., Pavlou, P., \& Venkatraman, N. (2013). Digital business strategy: toward a next generation of insights.

Böhmer, M., Hecht, B., Schöning, J., Krüger, A., \& Bauer, G. (2011). Falling Asleep with Angry Birds, Facebook and Kindle - A Large Scale Study on Mobile Application Usage. Proceedings of the 13th International Conference on Human Computer Interaction with Mobile Devices and Services.

Brown, S. A., Venkatesh, V., \& Goyal, S. (2014a). Expectation confirmation in information systems research: a test of six competing models. MIS Quarterly, 38(3), 729-756.

Brown, S. A., Venkatesh, V., \& Goyal, S. (2014b). Expectation Confirmation in Information Systems Research: A Test of Six Competing Models. Mis Quarterly, 38.

Chung, J., \& Tan, F. B. (2004). Antecedents of perceived playfulness: an exploratory study on user acceptance of general information-searching websites. Information \& Management, 41, 869-881.

Csikszentmihalyi, M., \& Csikszentmihalyi, I. S. (1992). Optimal experience: Psychological studies of flow in consciousness.

Der Heijden, H. (2004). User acceptance of hedonic information systems. MIS Quarterly, 695-704.

Dickinger, A., Arami, M., \& Meyer, D. (2006). Reconsidering the adoption process: enjoyment and social norms - antecedents of hedonic mobile technology use. System Sciences, 2006. HICSS'06. Proceedings of the 39th Annual Hawaii International Conference on.

Fogel, J., \& Zachariah, S. (2017). Intentions to use the yelp review website and purchase behavior after reading reviews. Journal of theoretical and applied electronic commerce research, 12(1), 53-67.

Ghani, J. A., Supnick, R., \& Rooney, P. (1991). The Experience of Flow in Computer-mediated and in Faceto-face Groups. ICIS.

Greene, W. H. (2008). Econometric Analysis.

Guchait, P., \& Namasivayam, K. (2012). Customer creation of service products: role of frustration in customer evaluations. Journal of services Marketing, 26, 216-224.

Hirschman, E. C., \& Holbrook, M. B. (1982). Hedonic consumption: emerging concepts, methods and propositions. The Journal of Marketing, 46, 92-101.

Hoffman, D. L., \& Novak, T. P. (1996). Marketing in hypermedia computer-mediated environments: conceptual foundations. the Journal of Marketing, 50-68.

'Behavioral'addictions: do they exist?, American Association for the Advancement of Science (2001).

IDC. (2013). Worldwide and U.S. Mobile applications download and revenue 2013-2017 forecast: The app as the emerging face of the internet. In.

Knijnenburg, B. P., Willemsen, M. C., Gantner, Z., Soncu, H., \& Newell, C. (2012). Explaining the user experience of recommender systems. User Modeling and User-Adapted Interaction, 22, 441-504. 
Lazar, J., Jones, A., Hackley, M., \& Shneiderman, B. (2005). Severity and Impact of Computer User Frustration: A Comparison of Student and Workplace Users (2002). In.

Lenhart, A., Purcell, K., Smith, A., \& Zickuhr, K. (2010). Social Media \& Mobile Internet Use among Teens and Young Adults. Millennials. In Pew Internet \& American Life Project: Pew Internet \& American Life Project.

Lin, C.-P., \& Bhattacherjee, A. (2010). Extending technology usage models to interactive hedonic technologies: a theoretical model and empirical test. Information Systems Journal, 20, 163-181.

Lindell, M. K., \& Whitney, D. J. (2001). Accounting for common method variance in cross-sectional research designs. Journal of applied psychology, 86, 114.

Mallat, N. (2007). Exploring consumer adoption of mobile payments--A qualitative study. The Journal of Strategic Information Systems, 16, 413-432.

Mikalef, P., Giannakos, M., \& Pateli, A. (2013). Shopping and word-of-mouth intentions on social media. Journal of theoretical and applied electronic commerce research, 8(1), 17-34.

Nah, F. F.-H., Eschenbrenner, B., \& DeWester, D. (2011). Enhancing brand equity through flow and telepresence: A comparison of 2D and 3D virtual worlds. MIs Quarterly, 731-747.

Shin, C., Hong, J.-H., \& Dey, A. K. (2012). Understanding and prediction of mobile application usage for smart phones. Proceedings of the 2012 ACM Conference on Ubiquitous Computing.

Srivastava, S. C., Chandra, S., \& Theng, Y.-L. (2010). Evaluating the role of trust in consumer adoption of mobile payment systems: An empirical analysis. Communications of the Association for Information Systems, 27, 561-588.

Sun, H., \& Zhang, P. (2006). Causal relationships between perceived enjoyment and perceived ease of use: An alternative approach. Journal of the Association for Information Systems, 7, 24.

Trevino, L. K., \& Webster, J. (1992). Flow in computer-mediated communication electronic mail and voice mail evaluation and impacts. Communication Research, 19, 539-573.

Turel, O., Serenko, A., \& Bontis, N. (2010). User acceptance of hedonic digital artifacts: A theory of consumption values perspective. Information \& Management.

Venkatesh, V., Brown, S. A., Maruping, L. M., \& Bala, H. (2008). Predicting different conceptualizations of system use: the competing roles of behavioral intention, facilitating conditions, and behavioral expectation. MIS quarterly, 483-502.

Venkatesh, V., Morris, M. G., Davis, G. B., \& Davis, F. D. (2003). User acceptance of information technology: Toward a unified view. Mis Quarterly, 425-478.

Venkatesh, V., Thong, J., \& Xu, X. (2012). Consumer acceptance and use of information technology: Extending the unified theory of acceptance and use of technology. Mis Quarterly, 36, 157-178.

Wakefield, R. L., \& Whitten, D. (2006). Mobile computing: a user study on hedonic/utilitarian mobile device usage. European Journal of Information Systems, 15, 292-300.

Wells, J. D., Valacich, J. S., \& Hess, T. J. (2011). What signal are you sending? How website quality influences perceptions of product quality and purchase intentions. MIS quarterly, 373-396.

White, H. (1980). A heteroskedasticity-consistent covariance matrix estimator and a direct test for heteroskedasticity. Econometrica: Journal of the Econometric Society, 817-838.

Wilfong, J. D. (2006). Computer anxiety and anger: The impact of computer use, computer experience, and self-efficacy beliefs. Computers in Human Behavior, 22, 1001-1011.

Xu, J., Benbasat, I., \& Cenfetelli, R. (2013). Integrating service quality with system and information quality: an empirical test in the e-service context. Mis Quarterly, 37, 777-794. 